\title{
Construção da identidade docente na licenciatura dupla em Biologia e Química: contribuições do currículo
}

\author{
Constructing teacher identity in a Chemistry and Biology teaching \\ degree course: curricular contributions
}

\section{La construcción de identidad docente en la licenciatura conjunta en Biología y Química: contribuciones del currículum}

Sidilene Aquino de Farias 1

https://orcid.org/0000-0003-3866-207X

Ana Cris Nunes de Souza ${ }^{2}$

https://orcid.org/0000-0002-1259-864X

\begin{abstract}
Resumo: $O$ objetivo deste trabalho foi investigar a contribuição da configuração curricular de um Curso de Licenciatura Dupla em Biologia e Química (LDBQ), de uma Instituição de Educação Superior na Região Norte do país, na construção da identidade docente. A coleta de dados foi baseada na análise documental do Projeto Pedagógico do Curso, utilizando a Análise Textual Discursiva. Os resultados apontam que a LDBQ foi criada para atender a necessidade do contexto local, de professores com formação na área de Biologia e Química. $O$ perfil profissional e a identidade do curso apontam para um profissional que irá atuar na Educação Básica e em outros segmentos, como atuação técnico em nível superior. E, ainda, foram observados princípios formativos, como contextualização, interdisciplinaridade, articulação teoria e prática, transposição didática e investigação no ensino, havendo, porém, a necessidade de integração de conhecimentos específicos das áreas de Biologia e Química com pedagógicos.
\end{abstract}

Palavras-chave: Formação de professores. Currículo. Identidade docente.

Abstract: This study investigated the curricular contributions of a Chemistry and Biology teaching degree (LDBQ, Portuguese acronym) in a Higher Education Institution in the north of Brazil to the construction of teacher identity. The data was generated from the documet analysis of the Pedagogical Project of the course followed by a Discursive Textual Analysis. The results demonstrate that the LDBQ was designed to meet the needs of the local context of Biology and Chemistry teachers. The professional profile and course identity indicate the kind of professional that will teach in Basic Education as well as act in other segments as a technician with

\footnotetext{
' Doutora pela Universidade Federal de São Carlos. Docente do Departamento de Química e dos Programas de Pós-Graduação em Química (PPGQ) e Ensino de Ciências e Matemática (PPGECIM), da Universidade Federal do Amazonas. E-mail: sfarias@ufam.edu.br

${ }^{2}$ Mestre em Química, na linha de pesquisa Ensino de Química pela Universidade Federal do Amazonas. Professora da Secretária de Educação do Estado do Amazonas, no município de Coari-AM. E-mail: anacriscoari@gmail.com
}

Olhar de professor, Ponta Grossa, v. 24, p. I-I5, e-15398.004, 2021.

Disponível em <https://revistas2.uepg.br/index.php/olhardeprofessor> 
higher education. The study also observed the formative principles such as contextutalization, interdisciplinarity, theory and practice articulation, didactic transpositon and teaching research. Neverthless, it is still necessary to integrate the spcecific knowledge of Biology and Chemistry with teaching knowledge.

Keywords: Teacher Education. Curriculum. Teacher Identity.

Resumen: El objetivo de este trabajo fue investigar el aporte de la configuración curricular de un Curso de Doble Graduación en Biología y Química (LDBQ), de una Institución de Educación Superior en la Región Norte del país, en la construcción de la identidad docente. La recolección de datos se basó en el análisis documental del Proyecto Pedagógico del Curso, utilizando el Análisis Textual Discursivo. Los resultados muestran que la LDBQ fue creada para satisfacer las necesidades del contexto local, para profesores con formación en las áreas de Biología y Química. El perfil profesional y la identidad del curso apuntan a un profesional que trabajará en Educación Básica y en otros segmentos, como es el nivel superior. También se observaron principios formativos como la contextualización, la interdisciplinariedad, la articulación entre teoría y práctica, la transposición didáctica y la investigación en docencia. Sin embargo, persiste la necesidad de integrar conocimientos específicos en las áreas de Biología y Química con los pedagógicos.

Palabras-clave: Formación de professores. Currículum. Identidad docente.

\section{Introdução}

A identidade docente tem sido foco de pesquisas em diferentes áreas do conhecimento, em decorrência de ser construída por meio de um processo formativo contínuo, de forma representacional do ser e fazer do professor, no decorrer da sua trajetória escolar e profissional. Dessa forma, o estudo das políticas educacionais que regulam os cursos de licenciatura desvela novos elementos capazes de contribuir rumo a novas óticas da formação inicial e a construção da identidade docente do licenciando. A formação docente ou o aprender ser professor ocorre de forma contínua, no diálogo entre o currículo da formação inicial e a formação permanente, isto é, ao longo do período de desenvolvimento profissional (GARCIA, 1992; NÓVOA, 1992; MIZUKAMI, 1996).

Considerando o contexto da Amazônia, as identidades locais também sofreram mudanças decorrentes dos fatores da globalização, a qual tem ocasionado um conflito entre identidades tradicionais e as novas propostas identitárias. Desse modo, o objetivo deste trabalho foi investigar a contribuição da configuração curricular de um Curso de Licenciatura Dupla em Biologia e Química (LDBQ) na construção da identidade docente, pois se torna relevante verificar como esse curso estrutura o seu currículo prescrito para a formação em uma licenciatura dupla e de que forma está favorecendo a formação de saberes pedagógicos.

Vale ressaltar que a realização deste estudo neste curso decorre de alguns questionamentos e inquietações referentes ao seu caráter duplo, abrangendo duas áreas de conhecimento e por tratar-se de uma estratégia de formação docente na Região Amazônica, que vem contribuindo para amenizar a carência de professores com formação específica nas áreas de Ciências, para atuar na Educação Básica.

Diante disso, procurou-se averiguar as peculiaridades e natureza desse curso, sua configuração curricular, como ocorre a interface entre os saberes específicos de Biologia e Química e os 
conhecimentos pedagógicos, tendo em vista promover reflexões acerca da construção da identidade profissional docente do egresso.

$\mathrm{Na}$ modernidade tardia, as antigas identidades nacionais, que por um longo período foram fixas, estão sendo enfraquecidas mediante o surgimento de identidades fragmentadas e definidas conforme a história de vida, identificações e representações dos sujeitos nos meios social e cultural nos quais estes se posicionam e assumem diferentes papéis sociais. Vale ressaltar que as múltiplas identidades permanecem em contínua transformação (WOODWARD, 2000; GIDDENS, 2005; DUBAR, 2006; HALL, 2006; ZANATTA, 20II). Em decorrência da globalização e o mercado transnacional, surgiu uma crise nas identidades coletivas, culturas locais e pessoais, pois o avanço acelerado dos meios de comunicação, da migração, da quebra de fronteiras e da difusão das culturas favoreceu a homogeneidade cultural e hibridismos identitários, sendo algumas identidades fortalecidas, reafirmadas e outras até geradas.

Nesse processo, são destacados dois tipos de identidades: pessoal (autoidentidade), formada por meio das vivências sociais do sujeito, resultante das constantes negociações identitárias; e social, que se relaciona às percepções dos outros acerca do sujeito nos diversos ambientes em que ele participa (DUBAR, 1997, 2006, 20I2; GIDDENS, 2005; SANTOS, 2005; NASCIMENTO, 2007; ZANATTA, 20II).

No que tange à formação de professores, a identidade se constrói mediante vivências práticas e identificações com os discursos em disputa nos grupos sociais que frequentam, inclusive no ambiente profissional. Portanto, nos cursos de licenciatura, o currículo desenvolvido se configura em espaço privilegiado dos processos da construção identitária. Dessa maneira, a identidade docente se forma a partir da história de vida, saberes, valores, desejos, concepções de mundo, do fazer e ser professor (PIMENTA; ANASTASIOU, 2002; NASCIMENTO, 2007; ROSA et al., 2008; PIMENTA, 20I2).

Aproximando a construção da identidade profissional docente de um repertório de saberes, presentes no currículo de formação inicial, que possibilite analisar a prática educativa, destaca-se que o professor inicia suas experiências, construção dos saberes e identidade docente antes mesmo de sua formação acadêmica, isto é, no decorrer da sua vida familiar e escolar, acumulando conhecimentos e forjando tendências reprodutivas de docentes que marcaram sua vida na escola, como bons ou até mesmo péssimos profissionais (CARVALHO; GIL-PÉREZ, 20II; DUBAR, 2006; MALDANER, 20I3; NASCIMENTO, 2007; NÓVOA, 1992; PERRENOUD, 2002a; PIMENTA, 2012; PIMENTA; ANASTASIOU, 2002; TARDIF, 20I4).

A construção de diversos saberes na formação inicial integram a identidade docente, sendo estes: a) da Ciência da educação - doutrinas ou concepções provenientes de reflexões sobre a prática educativa, transmitidas pelas licenciaturas nas Instituições de Educação Superior (IES); b) 
Construção da identidade docente na licenciatura dupla em Biologia e Química...

Disciplinares - correspondem aos diversos campos do conhecimento que dispõem a nossa sociedade, tais como se encontram hoje integrados nas Universidades; c) Curriculares - discursos, objetivos, conteúdos e métodos a partir dos quais a instituição escolar categoriza e apresenta os saberes sociais; d) Experienciais - incorporam-se à experiência individual e coletiva sob a forma de hábitos e de habilidades, de saber fazer e de saber ser (TARDIF, 20I4).

Atualmente, a Resolução CNE/CP n 02/2019, de 20/12/2019, que institui as Diretrizes Curriculares Nacionais para a Formação Inicial de Professores para a Educação Básica e institui a Base Nacional Comum para a Formação Inicial de Professores da Educação Básica (BNC-Formação), aponta "a valorização da profissão docente, que inclui o reconhecimento e o fortalecimento dos saberes e práticas específicas de tal profissão" (BRASIL, 2019, p. 3). Para tal, estabelece 800 horas, que compreendem os conhecimentos científicos, educacionais e pedagógicos que possibilitam entender e pensar a educação e suas articulações com os sistemas, escolas e práticas educativas, sendo que esta dimensão currículo deve iniciar no primeiro do ano do curso. Nessa perspectiva, o licenciando, desde o início do curso, interage com conhecimentos das Ciências da Educação e, com isso, pode favorecer a construção da sua identidade docente.

Porém, é preciso considerar alguns aspectos que interferem na construção da identidade: o primeiro relaciona-se a como estão sendo monitorados os cursos de formação inicial de professores pelas IES; e o outro diz respeito à problemática das estruturas desses órgãos e currículos e os fatores motivacionais de interesse por essa carreira profissional (GATTI, 20I4). É preciso, ainda, a integração entre as disciplinas científicas e as pedagógicas, pois a ausência dessa integração sinaliza a necessidade de um projeto de formação de professores articulado, sendo necessário o acompanhamento da sua execução.

Nessa perspectiva, o professor não deve apenas se apropriar do conhecimento científico da sua área de atuação, mas deve ser capaz de utilizar a diversidade de saberes que norteiam a sua prática pedagógica, cabendo ao curso de licenciatura, em seu Projeto Pedagógico do Curso (PPC), propiciar saberes docentes necessários para a formação identitária do professor. Pimenta (2012) nos esclarece a relevância do professor ser consciente no momento da manipulação dos saberes docentes, para a ressignificação de sua atividade docente.

\section{Metodologia}

Esta pesquisa de caráter qualitativo apresenta um recorte de uma dissertação de mestrado. A pesquisa qualitativa tem como objeto de estudo um conjunto de significados, motivações, desejos, valores, atitudes e crenças, sendo de caráter descritivo e exploratório, (BOGDAN; BIKLEN, 1994; 
MINAYO, 2012). Assumindo que a construção da identidade não é algo estático e acabado, mas em constante transformação, buscou-se interpretar as estruturas simbólicas que envolvem o universo do pesquisador e objeto a ser investigado em suas dimensões históricas e sociais, no intuito de entender como foi realizada a formação da identidade docente do egresso da LCBQ.

A pesquisa foi realizada no curso de LCBQ, que funciona no Instituto de Saúde e Biotecnologia/UFAM do município de Coari, localizado no interior do Estado do Amazonas. O curso teve seu início em 2006, com carga horária total de 4.145 horas, distribuídas em 10 semestres letivos, funcionando no período diurno, e oferta 50 vagas por ano. Ressalta-se que, quando da realização deste estudo, o curso não havia passado por nenhuma reestruturação.

A coleta de dados foi desenvolvida mediante a Análise Documental do PPC, com a utilização de um roteiro elaborado a partir da leitura dos referenciais teóricos, visando identificar os elementos no currículo prescrito que integram a identidade docente que o curso se propõe a formar (LÜDKE; ANDRÉ, 1986). No tratamento desses dados, utilizou-se a Análise Textual Discursiva (ATD), que consiste em uma metodologia de análise de dados qualitativos que caminha entre a análise de conteúdo e a análise de discurso. A linguagem tem um papel fundamental na ATD, tendo em vista que sua análise possibilita ao pesquisador a impregnação total no material analisado, em uma dinâmica de apreensão, construção e reconstrução de diferentes contextos.

Assim, o processo de análise seguiu algumas etapas, como: desmontagem dos textos; estabelecimento de relações, captando o novo emergente; e o processo auto-organizado. A desmontagem dos textos inicia-se pela leitura dos textos numa perspectiva de atribuir significados, a partir de conhecimentos, intenções e teorias e, em seguida, precisa definir e delimitar o conjunto de documentos que serão analisados, os quais recebem a denominação de corpus - trechos dos PPCs relacionados com o tema em estudo. Definido o conjunto de textos que serão analisados, inicia-se o processo de fragmentação dos textos para produzir as unidades de análise. Essa etapa é denominada de unitarização, em que o pesquisador irá fragmentar os textos e codificar cada unidade; depois, irá reescrevê-la, de modo a assumir um significado, o mais completo possível em si mesmo e, por fim, atribuirá um nome ou título para cada unidade produzida (MORAES; GALIAZZI, 2006; 20I I).

A partir dessa compreensão da ATD, tendo em vista a contribuição do currículo prescrito, no curso de LCBQ, nos processos de identificação docente, foi adotado o critério semântico na desconstrução dos textos, segundo o qual o contexto sócio-histórico do curso, os objetivos, o perfil do profissional a ser formado, as competências e habilidades, a matriz curricular, o formato dos estágios, as atividades complementares e ementas das disciplinas foram considerados nos recortes e possibilitaram atribuir significados e os seguintes temas: (I) criação e identidade do curso; (2)

Olhar de professor, Ponta Grossa, v. 24, p. I-2I, e-15594.005, 202 I. 
elementos curriculares que configuram a identidade; (3) princípios, modelos formativos e identidade docente.

Exemplificando como decorreu a análise, ao fazermos a leitura do PPC do curso, observamos que estava em vigência a primeira versão de currículo do curso, e o documento destacava justificativas de criação do curso pautadas nas necessidades e aspirações do município de Coari, em relação as demandas socioeconômicas e políticas, relativas à formação do professor. Dessa forma, buscaram-se os significados relativos à criação de um curso de formação de professores e processos de identificação, sendo proposto o tema Criação e Identidade do Curso. Rosa et al. (2008) mencionam que processos de identificação passam por uma rede de circunstâncias, sentimentos, histórias.

\section{Resultados e discussão}

$\mathrm{Na}$ análise do currículo prescrito, foram considerados os elementos como, o os itens como: objetivos, principais aspectos históricos e sociais do curso de LDBQ, forma de ingresso, habilidades e competências, atuação e perfil profissional, ementas das disciplinas. Mediante tais elementos a análise foi organizada mediante as seguintes temáticas: (I) Criação e Identidade do curso; (2) Elementos Curriculares que Configuram a Identidade Docente; (3) Princípios, Modelos Formativos e Identidade Docente.

\section{Criação e Identidade do Curso}

O curso de LDBQ começou a funcionar em novembro de 2006, à luz das normativas oficiais vigentes voltadas para a formação de professores da Educação Básica no Ensino Superior (BRASIL, 200 la, 2002), e das DCNs que regulam os cursos de Ciências Biológicas e Química (BRASIL, 200 Ib e 200 lc). Nesse contexto, percebeu-se que a princípio, a elaboração do PPC ocorreu sem um conhecimento mais aprofundado da realidade na qual a instituição está inserida, apontando-se a necessidade de rever este documento, tendo em vista inserir no mesmo, as visões e expectativas dos diferentes segmentos que vivenciam o curso de LDBQ. A construção da identidade docente deve perpassar o currículo, as discussões e os objetivos prescritos implementados pela instituição referente à formação de professores (FERREIRA; KASSEBOEHMER, 20I2). Vale salientar, que a licenciatura deve ter autonomia na elaboração de sua proposta pedagógica, devendo estar coerente com as particularidades próprias da identidade do curso, incluindo as especificidades das demandas sociais, econômicas e culturais locais (BRASIL, 200 la; ROSA et. al., 2008; PIMENTA, 20I2).

Nessa perspectiva, foi possível observar no PPC apontamentos sobre as necessidades do contexto Socioeconômico e Político, quando destacados o contexto educacional e mercado de 
trabalho como sendo aspectos determinantes na criação do curso. A subcategoria contexto educacional se relaciona à formação de um professor que contemple: uma sólida capacitação nas áreas de Biologia e Química; e ensino e pesquisa que envolva o contexto local, consciência ambiental e a formação para a cidadania. Dessa forma, notou-se que criação do curso investigado visava o desenvolvimento educacional da realidade local, por intermédio da pesquisa e ensino, e da produção mais aprofundada do conhecimento regional, nas áreas da Ciência da Natureza. Veiga (20I3, p. 13) menciona que o PPC deve: "estar intimamente articulado ao compromisso sociopolítico com os interesses reais e coletivos da população majoritária" (Quadro I).

De acordo com o PPC da LDBQ, o curso não somente buscar atender as normativas oficiais vigentes, mas também estar alinhado ao contexto local, tendo como finalidade produzir conhecimento referente ao contexto amazônico, por meio do desenvolvimento da pesquisa e ensino; contribuir com o ensino de Ciências de qualidade, as novas demandas escolares; e preencher a lacuna de profissionais para atuar na Educação Básica, com formação específica nas áreas de Biologia e Química. A esse respeito, Veiga (20I3) defende a relevância de o PPC apresentar aspectos identitários do contexto, onde a instituição de ensino está inserida.

Quadro I: Elementos que configuram a Identidade do Curso quando da sua criação, a partir do PPC.

\begin{tabular}{|c|c|c|}
\hline Categorias & $\begin{array}{c}\text { Subcategoria } \\
\text { s }\end{array}$ & Unidades de Significados \\
\hline \multirow{2}{*}{$\begin{array}{l}\text { Necessidades } \\
\text { Socioeconômic } \\
\text { as e Políticas }\end{array}$} & $\begin{array}{l}\text { Contexto } \\
\text { educacional }\end{array}$ & $\begin{array}{l}\text { [...] mirar a atualização dos conteúdos de formação às modificações } \\
\text { impostas ao ensino, à sociedade e à estrutura social e ambiental do } \\
\text { país em especial da região do Médio Solimões (p. 6). }\end{array}$ \\
\hline & $\begin{array}{l}\text { Mercado de } \\
\text { trabalho }\end{array}$ & $\begin{array}{l}\text { [...] se propõe a preencher esta lacuna, inserindo no mercado de } \\
\text { trabalho professores com base sólida em duas áreas de atuação ( } p \text {. } \\
\text { 4). }\end{array}$ \\
\hline \multirow{3}{*}{$\begin{array}{l}\text { Perfil } \\
\text { profissional a } \\
\text { ser formado }\end{array}$} & $\begin{array}{l}\text { Forma de } \\
\text { ingresso }\end{array}$ & $\begin{array}{l}\text { O ingresso no curso far-se-á mediante aprovação no Programa de } \\
\text { Seleção Macro Verão (PSMV) ou pelo Programa de Seleção } \\
\text { Contínua (PSC), sendo as vagas assim distribuídas: } 25 \text { vagas para o } \\
\text { PSMV e } 25 \text { vagas para o PSC (p. I5) }\end{array}$ \\
\hline & $\begin{array}{l}\text { Perfil do } \\
\text { egresso }\end{array}$ & $\begin{array}{l}\text { [...] preparação à aplicação pedagógica do conhecimento e } \\
\text { experiências dessas duas áreas [Biologia e Química] e demais } \\
\text { áreas afins na atuação profissional como educador na educação } \\
\text { fundamental e média (p. I0). } \\
\text { [...] o conhecimento profundo da diversidade dos seres vivos, bem } \\
\text { como sua organização em diferentes níveis, suas relações } \\
\text { filogenéticas e evolutivas [...] ( } p \text {. I0). } \\
{[\ldots . .] \text { entendimento do processo histórico de construção do }} \\
\text { conhecimento nas áreas biológicas e químicas, no que diz respeito } \\
\text { a conceitos, princípios e teorias, bem como a compreensão do } \\
\text { significado das Ciências Biológicas e da Química para a sociedade } \\
{[\ldots . . .1 \text { (p. I0). }}\end{array}$ \\
\hline & $\begin{array}{c}\text { Atuação } \\
\text { profissional }\end{array}$ & $\begin{array}{l}\text { [...] atuação profissional como educador na educação fundamental } \\
\text { e média (p. lo). }\end{array}$ \\
\hline
\end{tabular}

Fonte: elaborado pelas autoras, 2020.

Olhar de professor, Ponta Grossa, v. 24, p. I-2I, e-15594.005, 202 I.

Disponível em <https://revistas2.uepg.br/index.php/olhardeprofessor> 
Construção da identidade docente na licenciatura dupla em Biologia e Química...

A temática Identidade do Curso foi organizada em duas categorias: perfil profissional a ser formado (Quadro I) e saberes formativos (Quadro 2). É relevante ser definido no PPC o perfil profissional a ser formado pelo curso, para que seja respaldada sua identidade e suas particularidades, isto é, mesmo que se trate da formação de um bacharel ou do licenciado (FERREIRA; KASSEBOEHMER, 20I2).

A forma de ingresso, realizada no processo de seleção para o curso, ocorre mediante aprovação do candidato no processo seletivo do Programa de Seleção Macro Verão ou Programa de Seleção Contínua. Assim, a escolha profissional, se confirma durante a formação inicial do professor, sendo sua identidade em constante construção, no decorrer de todo o seu percurso profissional (PIMENTA; LIMA, 20II). Ressalta-se que a escolha profissional acontece quando o indivíduo se candidata para uma vaga em um determinado curso e durante a sua formação inicial. Todavia, essa escolha pessoal pode ser conflituosa, tendo em vista a baixa valorização social construída historicamente sobre ser professor, havendo baixa expectativa e falta de identificação com a docência, que constituem elementos que apontam a crise na construção da identidade docente (PIMENTA, 2006). Diante desse quadro são importantes estudos com licenciandos ingressantes e egressos desse curso, buscando entender as especificidades locais e expectativas que os movem a ingresso e conclusão do curso.

No que tange ao perfil do egresso, o PPC propõe um perfil de caráter generalista, abrangente e sólido, tanto na área de Biologia como na área de Química, por meio do domínio de saberes pedagógicos pertinentes ao ofício do magistério. Percebendo-se assim, que o perfil do egresso proposto no documento, estar à luz das normativas oficiais vigentes, que preceituam a elaboração dos cursos de licenciatura.

Por fim, no que se refere à subcategoria atuação profissional, o documento revelou que o curso visa preparar o egresso para atuar como professor da Educação Básica, nas áreas de Biologia e Química. Devendo este ser um profissional consciente, crítico, criativo, responsável e autônomo, que contribua na formação de cidadãos e domine estratégias alternativas na resolução dos problemas referente ao processo ensino e aprendizagem. Verificou-se também que, o egresso desse curso poderá atuar como docente ou como técnico de laboratório no Ensino Superior, devendo também estar preparado para prosseguir sua formação acadêmica em cursos de pós-graduação ou na área de Educação, ou Biologia/ou Química, ou em áreas correlatas. Desse modo, observou-se no documento que o egresso também deve dominar técnicas para atuar com pesquisa ou em laboratório. Em relação a pesquisa, não fica claro que seja pesquisa científica sobre o Ensino, visando a formação de professorpesquisador da sua prática.

Olhar de professor, Ponta Grossa, v. 24, p. I-2I, e-15594.005, 202 I. 
Dessa maneira, percebeu-se no currículo prescrito, que o curso de LDBQ apresenta a proposta da formação de um professor com perfil profissional a ser formado, todavia, é necessário que sejam apresentados todos os segmentos envolvidos de forma clara o tipo de modelo docente que o curso pretende adotar e as estratégias a serem realizadas para atingir esta formação. Aparentemente, o curso aponta para a formação de bacharéis concorrendo com a formação docente. A construção da identidade peculiar ao curso de licenciatura, tanto tem o intuito de valorizar a profissão do professor como visa romper concepções errôneas dos próprios docentes formadores, sendo necessárias nessa construção vivências práticas e identificações com os discursos que se traduzem tanto no currículo proposta pela instituição, quanto na condução desse curso por meio dos seus agentes sociais (PIMENTA; ANASTASIOU, 2002; NASCIMENTO, 2007; ROSA et. al., 2008; FERREIRA; KASSEBOEHMER, 20I2; PIMENTA, 20I2).

Diante disso, buscou-se compreender o curso LDBQ a partir dos saberes formativos dispostos na matriz curricular. As subcategorias foram organizadas conforme os saberes profissionais docentes de Tardif (20I4): saberes da ciência da educação, saberes disciplinares, saberes curriculares e saberes da experiência (Quadro 2). Constatou-se que os saberes da ciência da educação estão fundamentados, como: críticos-contextuais, pedagógicos e didático-curriculares; mediante a articulação teoria e prática e a integração dos componentes curriculares científicos e pedagógicos da matriz curricular, por intermédio de atividades de ensino, pesquisa e extensão.

Quadro 2: Saberes Formativos presentes no Curso LDBQ de acordo com o currículo proposto.

\begin{tabular}{|c|l|}
\hline Categorias & \multicolumn{1}{c|}{ Unidades de Significados } \\
\hline $\begin{array}{c}\text { Saberes da Ciência } \\
\text { da Educação }\end{array}$ & $\begin{array}{l}\text { Refletir sobre os fundamentos teórico-metodológicos da educação e suas implicações na } \\
\text { formação e nas práticas educativas dos educadores e as influências na elaboração do } \\
\text { planejamento educacional [...] (p. 46). }\end{array}$ \\
\hline Saberes Disciplinares & $\begin{array}{l}\text { Ter compreensão clara dos conceitos fundamentais em química relacionando os } \\
\text { conteúdos teóricos com o cotidiano. } \\
\text { Apresentar noções básicas de reatividade e a evolução histórica e conceitual das teorias } \\
\text { químicas. (p. 49). }\end{array}$ \\
\hline Saberes Curriculares & $\begin{array}{l}\text { Estruturação de aulas práticas para o ensino de biologia e química no ensino médio. } \\
\text { Compreender a correlação de estratégias necessárias à formação do professor de } \\
\text { biologia e química. (p. 79). }\end{array}$ \\
\hline Saberes Experienciais & $\begin{array}{l}\text { [...] planejamento e a programação dos conteúdos de Ciências em Ensino Fundamental } \\
\text { e Biologia e Química no Ensino Médio propiciar-lhes a vivência e a reflexão da prática } \\
\text { docente (p. 8I). }\end{array}$ \\
\hline
\end{tabular}

Fonte: elaborado pelas autoras, 2020.

A formação inicial necessita apresentar um currículo que integre o conjunto de disciplinas, em que suas intencionalidades e saberes desenvolvidos articulem teoria e prática, contribuindo para a ressignificação dos saberes do professor e identidade docente. A respeito disso, percebeu-se que a proposta de um arcabouço de conhecimentos pedagógicos formativos e contextualizados, de caráter

Olhar de professor, Ponta Grossa, v. 24, p. I-2I, e-15594.005, 202 I.

Disponível em <https://revistas2.uepg.br/index.php/olhardeprofessor> 
Construção da identidade docente na licenciatura dupla em Biologia e Química...

teórico e prático como: organização do sistema educacional; fundamentos, diretrizes e modelos educacionais; e aprendizagem de conceitos e estratégias para o ensino de Biologia e Química.

Em relação aos saberes pedagógicos, Tardif (2014) ressalta que estes constituem os saberes da ciência da educação, consistem em doutrinas teóricas utilizadas na prática educativa. Baseando-se neste pressuposto, compreende-se que o curso propõe saberes educativos, que visem conhecimentos que construam a identidade do professor no licenciando, relativos à prática educativa e seus embasamentos teóricos e contextuais.

Também se espera que o curso promova saberes crítico-contextuais, que favoreçam um olhar crítico do contexto social, econômico, político e cultural e suas influências na prática educativa, especialmente da realidade da Região Amazônica, devendo ser um agente transformador do meio em que está inserido.

No que diz respeito à subcategoria dos saberes disciplinares, notou-se que estes são pertinentes aos diferentes campos de conhecimentos dos componentes curriculares de formação do professor nas áreas de Biologia e Química. Tendo como proposição, a integração desses conhecimentos, envolvendo aspectos sócio-históricos e humanísticos, referentes a valores, significados sociais, princípios éticos, democráticos e legais. Assim, esta proposta converge com o pensamento de Tardif (2014), ao recomendar a superação de saberes disciplinares fragmentados pelas IES, para a formação identitária do professor.

No que concerne aos saberes curriculares, observou-se no PPC, que estes se configuram como didáticos-curriculares, sendo relativos à organização do trabalho educativo do professor de Biologia e Química e a ainda as concepções da cultura local, pertinentes aos diferentes segmentos do curso, que enriquecem e integram os conhecimentos, em suas diferentes interações. Vislumbrou-se que o curso além de propor integrar as disciplinas de Biologia e Química, também apresenta a proposta da valorização da cultura e saberes tradicionais peculiares ao contexto amazônico.

Percebendo-se que além de atividades formativas referentes aos elementos que constituem o planejamento, escolha e construção de recursos didáticos alternativos, práticas de laboratórios, elaboração de projetos didáticos e manuseio das Tecnologias da Informação e Comunicação (TIC), a proposta do curso sinaliza como competências: práticas democráticas; respeito à diversidade social e a biodiversidade regional.

No que diz respeito aos saberes experienciais, revelam-se nas ementas das disciplinas dos componentes curriculares da Prática como Componente Curricular (PCC), Estágio Curricular Supervisionado (ECS) e Atividades Acadêmico-Científico-Culturais (AACC), apontando a promoção de conhecimentos formativos, referentes à socialização profissional e a construção da identidade do

Olhar de professor, Ponta Grossa, v. 24, p. I-2I, e-15594.005, 202 I.

Disponível em <https://revistas2.uepg.br/index.php/olhardeprofessor> 
professor no ambiente de trabalho, mediante as vivências durante as atividades práticas e estágio no contexto escolar.

O que caracteriza os saberes práticos ou experienciais, de um modo geral, é o fato de originarem da prática cotidiana da profissão e serem por ela validados. Ora, nossas pesquisas indicam que, para os professores, os saberes adquiridos através da experiência profissional constituem os fundamentos de sua competência. É a partir deles que os professores julgam sua formação anterior ou sua formação ao longo da carreira (TARDIF, 20I4, p. 48).

Nessa perspectiva, o currículo prescrito em suas disciplinas de cunho pedagógico específico busca propiciar saberes experienciais que fortaleçam a formação identitária do professor de Biologia e Química, mediante experiências construídas nas práticas complementares, prática curricular e no estágio, pertinentes ao ensino, pesquisa e extensão.

Por fim, constatou-se que o curso de LDBQ tem como proposta a formação profissional de um professor, para atuar no ensino básico, no qual apresentou no seu PPC uma formação inicial conforme o que preconiza Tardif (2014) organizada com base na experiência prática e nos seguintes saberes profissionais: cultural (geral); científico (disciplinar); e dimensão pedagógica (Psicologia da aprendizagem, Sociologia da Educação, Didática).

\section{Elementos Curriculares que Configuram a Identidade Docente}

Quando da elaboração da proposta do curso, as orientações oficiais estabeleciam nas DCN para a formação de professores da Educação Básica no Ensino Superior o cumprimento pelos cursos de licenciatura da carga horária de 2.800h (BRASIL, 2002). Por se tratar de uma licenciatura dupla, com a finalidade de integrar as áreas de conhecimento Biologia e Química, o curso tem carga horária de 4. I45h, distribuída em dez períodos letivos.

Ao observar a carga horária dos componentes curriculares do curso, constatou-se que os conteúdos específicos representam o total de $63,80 \%$ da carga horária, sendo constituídos pelos seguintes componentes curriculares: fundamentos de Biologia e Química (46,40\%); e os conhecimentos da base curricular, Física (2,20\%), Matemática $(5,10 \%)$ e Complementares $(10,10 \%)$. Já os conteúdos voltados para a formação geral e específica do professor compreendem a carga horária de apenas $32,70 \%$, sendo representados pelos componentes curriculares: conhecimento pedagógico geral ou puro (8,00\%); PCC (10,10\%); ECS (9,80\%) e AACC (4,80\%) (Figura I).

Tornou-se perceptível, no currículo, que há uma maior carga horária alocada para os componentes curriculares de conhecimento específico do que para os componentes curriculares de formação. A formação pedagógica nos cursos de licenciatura desenvolve-se de forma superficial, prejudicando a formação de profissionais para atuarem nas escolas da atualidade, sendo reduzida a

Olhar de professor, Ponta Grossa, v. 24, p. I-2I, e-15594.005, 202 I.

Disponível em <https://revistas2.uepg.br/index.php/olhardeprofessor> 
Construção da identidade docente na licenciatura dupla em Biologia e Química...

carga horária direcionada às atividades formativas teóricas e práticas (GATTI, 20I4). Todavia, percebese que se tornam indispensáveis os conhecimentos sólidos de caráter pedagógico para a formação da identidade do professor, pois estes conhecimentos fundamentam a prática de ensino dele, possibilitando a articulação destes aos conhecimentos específicos (Biologia e Química). A esse respeito, Maldaner (2013, p. 45) questiona as IES e os cursos de licenciatura: "As universidades têm tido dificuldade de superar esse fosso que separa a formação pedagógica da formação específica no campo de conhecimento em que vai atuar".

Figura I: Distribuição percentual da carga horária dos componentes curriculares da Licenciatura Dupla em Ciências: Biologia e Química.

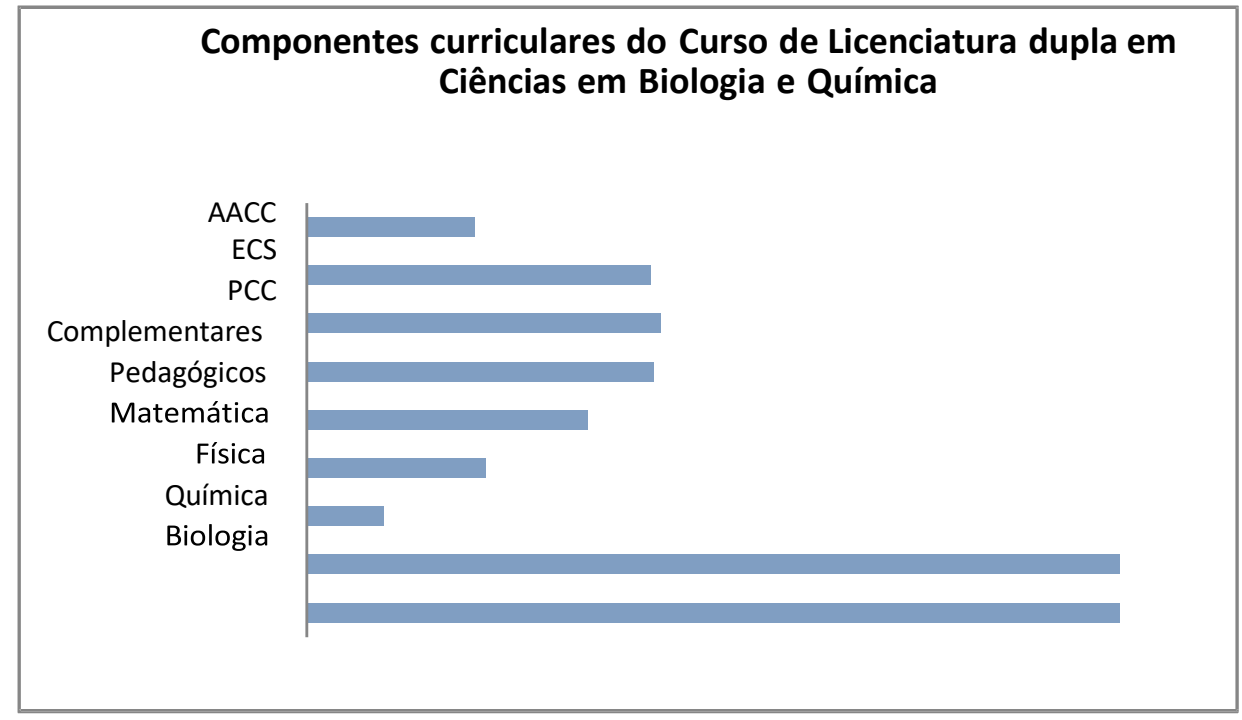

Fonte: elaborado pelas autoras, 2018.

Os conhecimentos complementares são compostos pelos conteúdos do eixo estruturante do curso de Fundamentos filosóficos e Sociais (I80h), constituídos pelas disciplinas de Filosofia, Sociologia e Antropologia, e pelo eixo estruturante Comunicação e Informática (I40h), que contemplam as disciplinas: Língua Portuguesa, Língua Inglesa, Informática Básica, inclusive LIBRAS.

Quanto aos conhecimentos pedagógicos, de acordo com a Consulta CNE/CES 197/2004, I/5 da carga horária total da licenciatura, sem incluir a PCC e o ECS, deve ser atribuída à formação pedagógica pura (BRASIL, 2004). Dessa forma, as disciplinas de formação pedagógica geral ou pura que constituem a matriz curricular do curso são: Psicologia da Educação (90h), Legislação do Ensino Básico (60h), Didática Geral (60h), e também como disciplinas obrigatórias foram inseridas na estrutura curricular: Gestão Organizacional (60h) e Metodologia do Estudo e Pesquisa (60h). A disciplina de Gestão Organizacional tem $\circ$ intuito de possibilitar compreensões concernentes ao trabalho, tecnologia e gestão, no sentido de entender as relações interpessoais no âmbito educacional. Nessa perspectiva, as disciplinas de fundamentos da educação subjazem uma formação teórica e prática, nas 
quais a licenciatura espera formar docentes críticos, viabilizando uma proposta de novas práticas educativas, cuja disciplinas devem desenvolver saberes e práticas que confluam nessa direção (PIMENTA; LIMA, 20I I).

No que concerne às PCC, verificou-se que está em consonância com as orientações oficiais, apresentando uma carga horária de 420h, distribuídas nas disciplinas "Prática Curricular I", com 90h; a II e III, com 60h. Além da Instrumentação para o Ensino de Biologia e Química I, com 90h, e Instrumentação para o Ensino de Biologia e Química II, com I20h, e também propondo que estas disciplinas realizem o papel de integração entre as duas áreas de formação e de articular teoria e prática, por meio das experiências educativas de extensão, pesquisa e ensino no contexto escolar. Essas disciplinas são ofertadas ao longo do curso, em que os licenciandos devem integrar as disciplinas pedagógicas e de conteúdo, a serem ensinados, de Biologia e Química, tornando-se relevante para possibilitar a construção de saberes profissionais referentes ao ser e fazer do professor.

As práticas pedagógicas atuarão como eixos articuladores entre as disciplinas componentes do currículo (PPC, p. 7).

Nesse sentido, o curso propõe práticas educativas e reflexivas que visem a transformação dos conteúdos específicos de Biologia e Química, em matéria de ensino, em que o mesmo deve mobilizar seus saberes docentes construídos no curso e articular teoria e prática, no intuito de reorganizar sua identidade profissional. A prática reflexiva implica que teoria e prática são indissociáveis, tendo um papel relevante na formação do professor, sendo o espaço que ocorrem as atividades educativas e a construção de saberes que modelam a identidade docente (ROSA; WEIGERT; SOUZA, 20I2).

O ECS foi estruturado em quatro etapas, totalizando $405 \mathrm{~h}$ distribuídas nos últimos quatro semestres letivos. Foi observado que, nos dois primeiros estágios, oportuniza-se ao licenciando a vivência na escola mediante momentos de observação, avaliação da realidade socioeducativa, enquanto os dois últimos momentos do estágio destinam-se à intervenção e atividades de regência, além de construção do conhecimento curricular e sua relação com o contexto. Vale ressaltar que, no quarto estágio, reúnem-se todos os dados para a elaboração do Trabalho de Conclusão de Curso (TCC). Os responsáveis pelo ECS são dois docentes formadores, cada um pertencendo a uma das áreas de formação específica, não sendo observado no documento detalhes de como ocorre a parceria entre o ISB/UFAM e as escolas. Para Pimenta e Lima (20II, p. II2): "na análise sistemática das práticas à luz das teorias, na elaboração de teorias, o que permite caracterizar o estágio como um espaço de mediação reflexiva entre a universidade, a escola e a sociedade".

Percebeu-se também que o ECS ainda tem como base uma concepção tradicional e técnica, no sentido que visualiza a escola como local de mera aplicação técnica dos conteúdos teóricos desenvolvidos na graduação, contrapondo a concepção de que ECS solidifica as competências 
Construção da identidade docente na licenciatura dupla em Biologia e Química...

trabalhadas no decorrer do curso, por meio de atividades formativas, que englobem conteúdos teóricos e práticos (BRASIL, 2005).

[...] os Estágios Supervisionados têm como objetivo a aplicação prática dos conhecimentos teóricos obtidos pelos alunos e devem ser desenvolvidos nas escolas da rede pública (PPC, p. 22).

No que se refere à AACC, o documento analisado evidencia como proposta a carga horária de 200h de atividades formativas diversificadas de ensino, pesquisa e extensão para o licenciando, por intermédio de novos conhecimentos e experiências referentes à área de atuação, que enriquecem o currículo do curso, podendo ser ofertadas pela instituição ou outros órgãos competentes, estando consoante com o que preconizam as normativas oficiais vigentes. Essas atividades são relevantes para a formação da identidade profissional do professor, pois proporcionam situações que envolvem o processo ensino e aprendizagem, de forma contextualizada e integrada.

Portanto, ao analisar as ementas das disciplinas que compõem a matriz curricular do curso, verificou-se que elas se apresentam fragmentadas, desarticulas das disciplinas de conhecimento científico de Biologia e Química e as disciplinas de formação pedagógica, apresentando-se uma configuração curricular pautada na racionalidade técnica, que desfavorece a formação identitária do professor. Dessa forma, observou-se que, para o currículo prescrito do curso, mesmo distribuindo-se as disciplinas da PCC e de formação pedagógica ao longo do curso, com um discurso de articulação entre a teoria e a prática, o conhecimento específico e o conhecimento pedagógico, falta organizar a matriz curricular e as ementas do curso, de forma a contribuir com uma maior integração dos diversos saberes necessários para a construção da identidade profissional do professor.

\section{Princípios, Modelos Formativos e Identidade Docente}

A proposta curricular do curso LDBQ também foi analisada visando identificar princípios, modelos formativos e a relação com a identidade docente. Nesse sentido, foram propostas cinco categorias e subcategorias de análise: interdisciplinaridade; contextualização; investigação no ensino; transposição didática; articulação teoria e prática; e professor como técnico e professor reflexivo (Quadro 3).

Foram observadas, no currículo, a interdisciplinaridade e a contextualização, ao se analisarem as ementas das disciplinas dos componentes curriculares PCC, ECS e AACC, verificandose o princípio da interdisciplinaridade e contextualização, mediante a proposta do curso de desenvolver temas transversais de forma contextualizada, que visem integrar as disciplinas dos conhecimentos científicos e os pedagógicos, tendo em vista conhecer a realidade local e suas peculiaridades, no qual deverá atuar. 
Com relação aos princípios formativos de articulação entre teoria e prática e transposição didática, foi observado nas ementas dos componentes curriculares PCC, ECS e AACC, que há uma proposta de relação entre conhecimentos teóricos e práticos desenvolvidos no curso, por meio das vivências no contexto escolar e prática de ensino, apresentando também a proposta de transformação do conhecimento, no conteúdo a ser ensinado por meio do conhecimento de estratégias de ensino e aprendizagem.

Quadro 3: Princípios e modelos formativos presentes no Curso LDBQ.

\begin{tabular}{|c|c|c|}
\hline Categorias & Subcategorias & Unidades de Significados \\
\hline \multirow{4}{*}{$\begin{array}{c}\text { Princípios } \\
\text { curriculare } \\
\text { s }\end{array}$} & $\begin{array}{l}\text { Interdisciplinaridade e } \\
\text { contextualização }\end{array}$ & $\begin{array}{l}\text { Conhecer os temas transversais e sua importância como articuladores } \\
\text { necessários a interdisciplinaridade e contextualização ( } p .8 I) \text {. }\end{array}$ \\
\hline & Investigação no ensino & $\begin{array}{l}\text { Analisar, através da pesquisa, os problemas e as dificuldades que o } \\
\text { ensino de Biologia apresenta [...] (p. 78). }\end{array}$ \\
\hline & Transposição didática & $\begin{array}{l}\text { Proceder à seleção e organização de conteúdos e a sua transposição } \\
\text { didática }[\ldots . .](\text { p. } 8 I) \text {. }\end{array}$ \\
\hline & $\begin{array}{l}\text { Articulação entre } \\
\text { teoria e prática }\end{array}$ & $\begin{array}{l}{[\ldots] \text { se faz necessário romper as dicotomias existentes entre a teoria e }} \\
\text { a prática }[\ldots] \text { (p. } 87) \text {. }\end{array}$ \\
\hline \multirow{2}{*}{$\begin{array}{l}\text { Modelos } \\
\text { formativos }\end{array}$} & $\begin{array}{l}\text { Professor como } \\
\text { técnico }\end{array}$ & $\begin{array}{l}\text { A investigação na Biologia e Química: questão teórica, prática de campo } \\
\text { e de laboratório (p. } 76) \text {. }\end{array}$ \\
\hline & Professor reflexivo & [...] propiciar-Ihes a vivência e a reflexão da prática docente (p. 8I). \\
\hline
\end{tabular}

Fonte: elaborado pelas autoras, 2020.

No que tange à Investigação no ensino, a análise das ementas das disciplinas dos componentes das PCC e ECS revelaram que há este princípio formativo, uma vez que se propõe a investigação no ensino de Biologia e Química, com o intuito de o licenciando se familiarizar com o ambiente de trabalho e suas dificuldades, identificando suas principais problemáticas, buscando a resolução dos problemas, mediante o desenvolvimento de diferentes estratégias e utilização de diversos recursos didáticos. Além disso, o PPC propõe que a Investigação no ensino deve aproximar a universidade e comunidade escolar por meio de ações de extensão, desenvolvidas nas disciplinas dos componentes curriculares da PCC, ECS e AACC, pelos licenciandos. Nesse sentido, entende-se que reflete o papel da formação inicial de propiciar aos futuros professores saberes conceituais, procedimentais e atitudinais, mediante a inquirição da prática de ensino e mobilização dos saberes na superação dos desafios no contexto escolar e formação identitária do professor (PIMENTA, 20I2).

Também foram observadas características que delineiam Modelos Formativos de professores, como o Professor reflexivo, pois foram identificados aspectos concernentes à experiência de pesquisa da prática docente, nas disciplinas da PCC, ECS e AACC, visando integrar os diversos saberes conceituais e metodológicos, para enxergar o ensino como espaço de reflexão da prática, das problemáticas e soluções, possibilitando a mobilização dos saberes e produção de conhecimentos na 
Construção da identidade docente na licenciatura dupla em Biologia e Química...

realidade escolar, e consequentemente da ressignificação da identidade do professor. A relevância da pesquisa no ensino para a formação do professor prático reflexivo, transformando-se em profissionais melhores, enquanto apreendem conhecimento mediante a investigação (ZEICHNER, 1998).

No entanto, o curso ainda apresenta características do modelo de Professor técnico, pois existe uma valorização curricular dos conhecimentos específicos em detrimentos dos conhecimentos pedagógicos, estando desarticulados estes conteúdos na matriz curricular. Também há a possibilidade de as atividades investigativas do ensino serem direcionadas apenas para a apropriação de técnicas ou estratégias pedagógicas, sem uma reflexão mais aprofundada da atividade educativa e transformação identitária do professor.

Desse modo, o PPC traz, em seu discurso, princípios formativos que buscam integrar os componentes curriculares, como: interdisciplinaridade; contextualização; articulação teoria e prática; transposição didática; investigação do ensino e a formação do professor reflexivo de sua prática, porém, apesar de a matriz curricular apresentar avanços no seu desenho, referentes à distribuição da PCC e ECS, ainda oferece, nas ementas do curso, princípios formativos de um professor técnico, em uma dicotomia referente à organização das disciplinas de caráter específico e pedagógico.

Portanto, a partir do documento analisado, verificou-se que a LDBQ, em seu discurso, traz princípios formativos e objetivos que favorecem a formação do perfil profissional de um professor reflexivo de Biologia e Química, para atuar na Educação Básica, necessitando ainda ser revista a matriz curricular do curso, visando integrar os divergentes componentes curriculares, e a teoria e prática, no sentido de garantir aos diferentes segmentos saberes que proporcionem a reflexão mais aprofundada da prática educativa, que almejem a formação da identidade profissional do egresso do curso.

Popkewits (1992, p. 46) nos remete que: "O pensamento pós-moderno torna-nos conscientes de que, por muitos nobres que sejam os nossos ensejos, um currículo é uma prática socialmente construída e politicamente determinada". Nesse sentido, não basta apenas o documento ser bem elaborado, mas torna-se de grande relevância a coerência entre a proposta curricular dos princípios formativos do curso com o currículo vivido, sendo necessário que os diferentes segmentos do curso se apropriem desta proposta, para que ela seja realmente implementada.

\section{Considerações finais}

As Instituições de Educação Superior que possuem cursos de formação inicial de professores para Educação Básica têm um papel relevante, pois desenvolvem saberes profissionais docentes nos futuros professores, que possibilitam a formação da sua identidade docente. Nesse sentido, este trabalho teve como objetivo analisar a formação da identidade profissional docente do egresso do 
curso de LDBQ do ISB do Médio Solimões, localizado em Coari-AM, à luz da perspectiva formativa do professor reflexivo.

Entende-se que a identidade profissional docente se desenvolve de forma processual, durante toda a vida, estando sempre se renovando. Os elementos que constituem a identidade profissional consistem em saberes desenvolvidos pelo professor, por meio de suas vivências e interações sociais, que configuram e direcionam suas atitudes, comportamentos, valores e escolhas pessoais e profissionais. Diante disso, várias identidades são concorrentes no curso LDBQ: a identidade do biólogo, do químico, do professor de Biologia, do professor de Química, e vão se entrelaçando no decorrer do processo formativo nas diferentes interações dos licenciandos com outros agentes sociais do curso e o desenvolvimento do currículo proposto.

Nessa perspectiva, a construção da identidade docente está relacionada à trajetória pessoal e profissional do professor, suas experiências na infância (família/escola), na formação inicial, mediante a imagem que ele tem de si como profissional e a partir do olhar dos seus pares no local de trabalho. Verifica-se, assim, que a identidade profissional do egresso apresenta-se bastante complexa, sendo difícil analisar sua configuração, porque ela está em constante construção, algo inerentemente relativo à história, à trajetória escolar e profissional de cada indivíduo e de suas experiências na formação inicial.

Dessa forma, mediante a análise do PPC, constatou-se que a LDBQ foi criada para atender a necessidade do contexto local, de professores com formação na área de Biologia e Química, visando à melhoria educacional do Ensino de Ciências nessas áreas na Educação Básica, na Região Amazônica. Por meio dessa análise, em relação ao perfil profissional formado pelo curso e sua identidade, concluiuse que o curso apresenta uma proposta formativa de um professor de Ciências para atuar na Educação Básica, no entanto, a matriz curricular do curso ainda está organizada de forma fragmentada, com conteúdos científicos e pedagógicos desarticulados, apresentando baixo grau de interdisciplinaridade.

Percebeu-se, também, a presença da concepção técnica no currículo, pois ainda existe maior valorização no currículo, dos conhecimentos específicos sob os conteúdos pertinentes à dimensão pedagógica. Necessita-se rever tais pontos no currículo prescrito e nas concepções desses sujeitos, no sentido de favorecer a formação identitária do professor. E, ainda, foram observados os seguintes princípios formativos: contextualização, interdisciplinaridade, articulação teoria e prática, transposição didática e investigação no ensino. Todavia, também se fazem necessárias reformulações no PPC, no sentido de a matriz curricular integrar os conhecimentos específicos das áreas de Biologia e Química, aos conhecimentos pedagógicos, devendo também ser mais bem detalhado o modelo de professor que o curso pretende formar.

Do exposto, depreende-se que o curso de LDBQ apresenta elementos favoráveis à construção da identidade profissional docente do egresso, entretanto, sendo necessárias algumas atualizações no 
PPC e matriz curricular, de modo que suas implementações pelos atores sociais possibilitem mudanças teóricas e práticas, que desenvolvam alterações na formação inicial, tanto na dimensão conceitual dos seus sujeitos como nas ações direcionadas para a formação identitária do professor.

É importante destacar, para além do currículo prescrito do curso, que a constituição das identidades depende de diferentes interpelações e negociações constantes que ocorrem na cultura das instituições acadêmicas. Isso suscita a busca de compreensão a partir de outros questionamentos, a saber: como essas negociações ocorrem nas interações dos atores sociais desse curso? Como os licenciandos percebem a constituição dessa identidade durante sua vivência no curso? Quais outras identidades profissionais coexistem nesse curso? Tais questionamentos, entre outros, necessitam de novos estudos longitudinais e transversais no curso, visto que diferentes dinâmicas de interação são estabelecidas nos cursos de formação e, com isso, marcam "diferentes formas de ser/estar em relação às identidades profissionais" (ROSA et. al., 2008, p. 157).

\section{Agradecimentos}

À Coordenação do Curso de Licenciatura Dupla em Biologia e Química.

À Coordenação de Aperfeiçoamento de Pessoal de Nível Superior - CAPES.

À Universidade Federal do Amazonas - UFAM.

\section{Referências}

BRASIL. Ministério da Educação. Parecer do CNE/CP n 009, de 08 de maio de 200 I. Diretrizes Curriculares Nacionais para a Formação de Professores da Educação Básica, em nível superior, curso de licenciatura, de graduação plena. Brasília, DF: MEC/CNE, 200la. Disponível em: <http://portal.mec.gov.br/sesu/arquivos/pdf/0090 Iformprof.pdf> Acesso em: 25 fev. 2020.

BRASIL. Ministério da Educação. Parecer do CNE/CES n I.30I, de 06 de novembro de $200 \mathrm{I}$. Diretrizes Curriculares para os cursos de Ciências Biológicas. Brasília, DF: MEC/CNE, 200lb. Disponível em: <http://portal.mec.gov.br/cne/arquivos/pdf/ CESI30I.pdf> Acesso em: 25 fev. 2020.

BRASIL. Ministério da Educação. Parecer do CNE/CES n I303, de II de novembro de 200 I. Diretrizes Curriculares Nacionais para os cursos de Química. Brasília, DF: MEC/CNE, 200 lc. Disponível em: http://portal.mec.gov.br/sesu/arquivos/pdf/ CPI3030IQuímica.pdf Acesso em: 25 fev. 2020.

BRASIL. Ministério da Educação. Resolução CNE/CP $\mathbf{n}^{\circ}$ I, de 18 de fevereiro de 2002. Institui Diretrizes Curriculares Nacionais para a Formação de Professores da Educação Básica, em nível superior, curso de licenciatura, de graduação plena. Brasília, DF: MEC/CNE, 2002. Disponível em: http://portal.mec.gov.br/cne/arquivos/pdf/CPOI2002. pdf>. Acesso em: 25 fev. 2020.

BRASIL. Ministério da Educação. Consulta, tendo em vista o art. I I da Resolução CNE/CP 1/2002, referente às Diretrizes Curriculares Nacionais para a Formação de Professores da Educação Básica em nível superior, curso de licenciatura em graduação plena. Brasília, 
DF: MEC/CNE, 2004. Disponível em: <http://portal.mec.gov.br/cne/arquivos/pdf/pces 197_04.pdf> Acesso em: 25 fev. 2020.

BRASIL. Ministério da Educação. Resolução CNE/CES n 15, de 02 de fevereiro de 2005. Solicitação de Esclarecimentos sobres as resoluções CNE/CP $n^{\circ} 1 / 2002$, que institui diretrizes curriculares para a Formação de Professores da Educação Básica, em nível superior, curso de licenciatura, graduação plena, e 2/2002, que institui a duração e carga horária dos cursos de licenciatura, graduação plena, para a Formação de Professores da Educação Básica. Brasília, DF: MEC/CNE, 2005. Disponível em: <http://www.ufv.br/sesu/arquivos/pdf/0090 Iformprof.pdf>. Acesso em: 25 fev. 2020.

BRASIL. Ministério da Educação. Resolução CNE/CP $\mathbf{N}^{\circ}$ 2, de 20 de dezembro de 2019. Define as Diretrizes Curriculares Nacionais para a Formação Inicial de Professores para a Educação Básica e institui a Base Nacional Comum para a Formação Inicial de Professores da Educação Básica (BNCFormação). Brasília, DF: MEC/CNE, 2019. Disponível em: < http://portal.mec.gov.br/docman/dezembro-2019-pdf/I3595I-rcp002-19/file>. Acesso em: 10 mar. 2020.

BOGDAN, R. C.; BIKLEN, S. K. Investigação qualitativa em educação: uma introdução à teoria e aos métodos. Traduzido por Maria João Alverez, Sara Bahia dos Santos e Telmo Mourinho Baptista. Portugal: Porto Editora, 1994. Tradução de Qualitative Research for Education. (Colecção Ciências da Educação).

CARVALHO, A. M. P.; GIL-PÉREZ, D. Formação de professores de ciências: Tendências e inovações. Traduzido por Valenzuela. 10. ed. São Paulo: Cortez, 20II.

DUBAR, C. A construção de si pela atividade de trabalho: A socialização profissional. Traduzido por Fernanda Machado. Cadernos de Pesquisa, v. 42, n. I46, p. 357-367, maio-ago. 2012.

DUBAR, C. A crise das identidades: A interpretação de uma mutação. Traduzido por Catarina Matos. Santa Maria da Feira: Edições Afrontamento, 2006.

DUBAR, C. Socialização: Construção das identidades sociais e profissionais. Traduzido por Annette Pierrette R. Botelho e Estela Pinto Ribeiro Lamas. 2. ed. Portugal: Porto Editora, 1997.

FERREIRA, L. H.; KASSABOEHMER, A. C. Formação inicial de professores de Química: A instituição formadora (re) pensando sua função social. São Carlos: Pedro \& João Editores, 2012.

GARCIA, C. M. A formação de professores: Novas perspectivas baseadas na investigação sobre o pensamento do professor. In: NÓVOA, A. (coord.). Os professores e a sua formação. Traduzido por Graça Cunha, Cândida Hespanha, Conceição Afonso e José Antônio Sousa Tavares. I. ed. Portugal: Publicações Dom Quizote, 1992. p. 5I-76.

GATTI, B. A. A formação inicial de professores para a Educação Básica: As licenciaturas. Revista USP, São Paulo. n. 100, p. 33-46, dez.-fev. 2013-20I4.

GIDDENS, A. Sociologia. Traduzido por Sandra Regina Netz. 4. ed. Porto Alegre: Artmed, 2005.

HALL, S. A identidade cultural na pós-modernidade. Traduzido por Tomaz Tadeu da Silva e Guacira Lopes Louro. I I. ed. Rio de Janeiro: DP\&A, 2006.

LÜDKE, M.; ANDRÉ, M. E. D. A. Pesquisa em educação: Abordagens qualitativas. São Paulo: EPU, 1986.

Olhar de professor, Ponta Grossa, v. 24, p. I-2I, e-15594.005, 202 I.

Disponível em <https://revistas2.uepg.br/index.php/olhardeprofessor> 
MALDANER, Otávio Aloisio. A formação inicial e continuada de professores de Química: Professores/pesquisadores. 4. ed. ljuí: Editora UNIJUÍ, 2013. (Coleção Educação em Química).

MINAYO, M. C. de S. Pesquisa social: Teoria, método e criatividade. 3I. ed. Petrópolis, RJ: Vozes, 2012.

MIZUKAMI, M. da G. N. Docência, trajetórias pessoais e desenvolvimento profissional. In: REALI, Aline Maria de Medeiros Rodrigues; MIZUKAMI, M. da G. N. (org.). Formação de professores: Tendências atuais. São Carlos: UFSCar, 1996. p. 59-9I.

MORAES, R.; GALIAZZI, M. C. Análise Textual Discursiva. 2. ed. ljuí: Unijuí, 201 I.

MORAES, R.; GALIAZZI, M. C. Análise textual discursiva: Processo reconstrutivo de múltiplas faces. Ciência \& Educação, v. I2, n. I, p. II7-I28, abr. 2006.

NASCIMENTO, M. A. V. Dimensões da identidade profissional na formação inicial. Revista Portuguesa de Pedagogia, v. 4I, n. 2, p. 207-2I8, 2007.

NÓVOA, A. Formação de professores e profissão docente. In: NÓVOA, A. (coord.). Os professores e a sua formação. Traduzido por Graça Cunha, Cândida Hespanha, Conceição Afonso e José Antônio Sousa Tavares. I. ed. Portugal: Publicações Dom Quizote, 1992. p. 13-33.

PERRENOUD, P. A formação dos professores do século XXI. In: PERRENOUD, P.; THURLER, M.G.; MACEDO, L. de; MACHADO, N.J.; ALLESSANDRINI, C.D. As competências para ensinar no século XXI: A formação dos professores e o desafio da avaliação. Traduzido por Cláudia Schilling e Fátima Murad. Porto Alegre, RS: Artmed, 2002. p. I I-33.

PIMENTA, S. G.; ANASTASIOU, L. das G. C. Docência no ensino superior. São Paulo: Cortez, 2002.

PIMENTA, S. G. Formação de professores: Identidade e saberes da docência. In: PIMENTA, S. G. (org.). Saberes pedagógicos e atividade docente. 8. ed. São Paulo: Cortez, 2012. p. 15-34.

PIMENTA, S. G.; LIMA, M. S. L. Estágio e Docência. 6. ed. São Paulo: Cortez, 201 I.

PIMENTA, S. G. Professor reflexivo: Construindo uma crítica. In: PIMENTA, S. G.; GHEDIN, E. (orgs.) Professor Reflexivo no Brasil: Gênese e crítica de um conceito. 4. ed. São Paulo: Cortez, 2006. p. 17-52.

POPKEWITZ, T. S. Profissionalização e formação de professores: Algumas notas sobre a história, ideologia e potencial. In: NÓVOA, A. (coord.). Os professores e a sua formação. Traduzido por Graça Cunha, Cândida Hespanha, Conceição Afonso e José Antônio Sousa Tavares. I. ed. Portugal: Publicações Dom Quizote, 1992. p. 35-50.

ROSA, J. K. L.; WEIGERT, C.; SOUZA, A. C. G. A. Formação docente: reflexões sobre o estágio curricular. Ciência \& Educação, v. 18, n.3, p. 675-688, nov. 2012.

ROSA, M. I. P.; OLIVEIRA, A. C. G.; PAVAN, A. C.; CORRADI, D. P. Formação de Professores de Química na Perspectiva da Cultura: reflexões sobre a noção de identidade profissional. In: ROSA, M. I. P.; ROSSI, A. V. (org.). Educação Química no Brasil: Memórias, Políticas e Tendências. Campinas, SP: Editora Átomo, 2008. p. 145-159. 
SANTOS, C. A construção social do conceito de identidade profissional. Interacções, n.8, p. 123I44, 2005.

TARDIF, M. Saberes docentes e formação profissional. Traduzido por Francisco Pereira. 12. ed. Petrópolis, RJ: Vozes, 2014.

VEIGA, I. P. A. Projeto político-pedagógico da escola: Uma construção coletiva. In: VEIGA, I. P. A. (org.). Político Projeto Político-Pedagógico da Escola: Uma construção possível. 29.ed. Campinas, SP: Papirus, 2013. (Coleção Magistério: Formação e Trabalho Pedagógico). p. II -52.

WOODWARD, K. Identidade e diferença: Uma Introdução teórica e conceitual. In: SIIVA, T. T. (org.). Identidade e diferença: A perspectiva dos Estudos Culturais. 5.ed. Petrópolis, RJ: Vozes, 2000. p. 772.

ZEICHNER, K. M. Para além da divisão entre professor-pesquisador e pesquisador acadêmico. In: GERALDI, C.M.; FIORENTINI, D.; PEREIRA, E.M. (orgs.). Cartografia do trabalho docente: professor(a)-pesquisador(a). Campinas: Mercado de Letras, ABL, 1998. p. 207-236.

ZANATTA, M. S. Nas teias da identidade: Contribuições para a discussão do conceito de identidade na teoria sociológica. Perspectivas. v. 35, n. I32, p. 4I-54, dez. $201 \mathrm{I}$.

Recebido em: 28 de maio de 2020.

Versão corrigida recebida em: 20 de setembro de 2020.

Aceito em: 20 de setembro de 2020.

Publicado online em: 12 de março de 2021 .

Olhar de professor, Ponta Grossa, v. 24, p. I-2I, e-15594.005, 202 I.

Disponível em <https://revistas2.uepg.br/index.php/olhardeprofessor> 